\title{
REVIEW JURNAL \\ SISTEM INFORMASI MANAJEMEN: PROMOSI KULINER DAN WISATA DI MEDIA SOSIAL
}

\author{
KELOMPOK 5 : \\ NI'MATUZZAHRA : C1B1 17194 \\ NINA : C1B1 17195 \\ RAHMAN : C1B1 17207 \\ MUH. APRIZAL : C1B1 17175
}

Program Studi Ilmu Pemerintahan

Fakultas Ilmu Sosial Dan Ilmu Politik

Universitas Halu Oleo

\section{Promosi Kuliner Jepang Melalui Media Sosial Sebagai Bentuk Diplomasi Publik : Studi Facebook Kedutaan Besar Jepang di Indonesia}

Permasalahan yang diangkat dalam membahas jurnal ini yaitu, mengenai promosi kuliner Kedutaan Besar Jepang di Indonesia melalui media sosial Facebook sebagai bentuk diplomasi publik. Diplomasi publik dipahami sebagai upaya suatu negara dalam mempromosikan tujuan nasional dengan memengaruhi opini publik di negara lain dengan pelibatan tidak hanya negara sebagai aktor namun juga aktor non negara dalam hal ini memungkinkan bagi masyarakat, baik secara individu maupun dalam kelompok untuk ikut serta.

Dalam mendukung untuk mengatasi masalah tersebut maka penelitian ini bertujuan untuk memperkenalkan budaya Jepang terutama kuliner-kuliner yang dimiliki oleh negara ini, agar publik dlam hal ini warga net dapat merasa senang, 
dekat sehingga tertarik dengan budaya dan wisata yang dieksplor di media sosial, hal ini dapat membuat diplomasi menjadi tak lagi berjarak.

Dalam jurnal ini menggunakan metode penelitian yang bersifat deskriptif kualitatif dengan subjek penelitian ialah media sosial Facebook Kedutaan Besar Jepang di Indonesia. Sedangkan teknik pengumpulan data dilakukan melalui wawancara, dan dokumentasi. Dalam penelitian ini yang menjadi informan yaitu admin Facebook Kedutaan Besar Jepang di Indonesia dan salah satu anggota Sekretariat Little Tokyo World Cosplay Summit Indonesia Kommitte. Adapun teknik analisa data yang digunakan dalam penelitian ini adalah analisis model interaktif yang berisi tahapan pengumpulan data, reduksi data, penyajian data, dan simpulan.

Hasil dari penelitian ini yaitu Hasil dari penelitian ini yaitu kedutaan besar jepang di indonesia menggunakan media sosial seperti facebook dalam mempromosikan kuliner hal ini merupakan cara yang efektif . Karena mengingat indonesia merupakan salah satu pengguna terbesar media sosial di dunia, pengguna facebook bukan hanya dari kalangan masyarakat bukan hanya dari kalangan masyarakat namun juga pemerintah sebagai media saling tukar menukar informasi, interaksi dua arah dan yang paling utama biaya yang sama sekali tidak memberatkan untuk membuat atau memiliki akun facebook. Hal ini juga mampu memberikan pemahaman serta citra yang baik bagi jepang oleh publik pengguna media sosial di indonesia yang dilihat dari jumlah pengikut, suka, dan komentar yang positif pada berbagai postingan admin facebook kedutaan besar jepang di indonesia.

Pemerintah Jepang mengembangkan dan melaksanakan berbagai kegiatan diplomasi publik di indonesia sebagai upaya untuk memperkuat hubungan jangka panjang bagi kedua negara dan tidak hanya menggunakan media sosial untuk mempromosikan kulinernya namun tetap mengembangkan dan melaksanakan program-program diplomasi publik dibidang pendidikan, kebudayaan, olahraga. 
People exchange dan lain-lain, serta meningkatkan rasa kepercayaan dan pemahaman terhadap publik di negara lain.

Saran yang dapat diberikan mengenai jurnal penelitian ini adalah selanjutnya peneliti mungkin dapat menampilkan mengenai hambatan-hambatan apa saja yang terjadi dalam promosi kuliner jepang di media sosial lewat facebook dan instagram. Dan dalam mempromosikan kuliner tersebut bisa di berikan penjelasan sedikit mengenai bahan atau kandungan apa saja yang digunakan dalam pembuatan menu kuliner tersebut, karena banyak menu kuliner dari Jepang yang tidak halal, dan melihat masyarakat Indonesia mayoritas muslim.

\section{PROMOSI PARIWISATA MELALUI DIGITAL DIPLOMACY: UPAYA INTERNASIONALISASI PARIWISATA DAERAH}

Permasalahan yang diangkat dalam pembahasan jurnal ini yaitu, mengenai promosi wisata daerah Wakatobi di kancah internasional melalui diplomasi digital. Karena masih sedikit ditemukan studi yang mengeksplor mengenai diplomasi digital sebagai instrument promosi wisata dalam level pemerintah daerah dibanding dengan studi yang membahas tentang implementasi fungsi teknologi informasi dan komunkasi dalam area pelayanan publik seperti e government, e planning, e budgeting. Oleh karena itu perlunya studi yang membahas tentang penggunaan internet danmedia sosial dalam diplomasi digital oleh Pemerintah Daerah.

Kemudian yang menjadi tujuan dalam penelitian ini yaitu untuk mengetahui diplomasi digital pemerintah daerah Wakatobi dalam mempromosikan pariwisata daerah dengan memberikan informasi terkait kepariwisataan kepada wisatawan asing di dunia internasional.

Metode penelitian yang digunakan yaitu metode kualitatif untuk mengetahui dan mengungkap fenomena yang terjadi. Wawancara digunakan sebagai sumber data dengan jumlah informan sebanyak tiga orang. Informan dalam penelitian ialah 
pegawai pada kantor Dinas Pariwisata dan Ekonomi Kretaif Kabupaten Wakatobi, yaitu Sekretaris Dinas, Kepala Bidang Pemasaran Dinas Pariwisata dan Ekonomi Kreatif, dan Staf Pengelola situs/website yang bertanggung jawab dalam diplomasi digital. Tujuan melakukan wawancara unutk mengeksplor opini dari kegiatan profesional informan dalam penggunaan TIK dan berdasarkan pengalaman dan keterlibatan mereka dalam aktivitas diplomasi digital dan promosi pariwisata Wakatobi. Data primer dalam studi ini bersumber dari hasil wawancara, sedangkan data sekunder didapatkan dari website dan media sosial yang digunakan Dinas Pariwisata dan Ekonomi Kreatif pemerintah Kabupaten Wakatobi dalam mempromosikan pariwisata Wakatobi. Model Analysis Interactivedari Miles dan Huberman (1994) digunakan sebagai analisis data dalam studi ini yang menggambarkan kegiatan analisis dalam beberapa tahapan pengumpulan data, reduksi data, penyajian data, dan penarikan kesimpulan atau verifikasi data.

Hasil dari penelitian ini yaitu Dinas Pariwisata dan Ekonomi Kreatif Kabupaten Wakatobi memanfaatkan media intenet sebagai salah satu media untuk mempromosikan pariwisata daerah seperti penggunaan Facebook, Instagram dan Twitter. Nama akun Facebookdan Instagram yaitu@visitwakatobi sedangkan untuk twitter dengan nama akun @tourismwakatobi. penggunaan media sosial oleh pemerintah daerah setidaknya telah memberdayakan hal-hal seperti (1) koneksi dan interaksi yang luasantara pemerintah dan publik di luar batas geografis, (2) manajemen hubungan jangka panjang melalui jejaring sosial dengan publik, (3) partisipasi dan keterlibatan publik serta (4) dapat memantau tanggapan publik terhadap pemerintah secara langsung (Park \& Lim, 2014; Romsdahl, 2005).

Selain menggunakan media sosial Dinas Pariwisata dan Ekonomi Kreatif Wakatobi menggunakan website resmi dalam memberikan informasi mengenai pariwisata Wakatobi. Website ini menggunakan dua Bahasa yaitu Inggris dan Indonesia. Website dinas pariwisata lahir dengan begitu banyak diversifikasi yang 
awalnya masih menggunakan wakatobi.info. Pada tahun 2016 itu kembali terjadi perubahan menjadi wakatobitourism.com yang bertahan sampai saat ini dan digunakan sebagai salah satu instrument pelaksanaan e-diplomacy.

Usaha tersebut dapat dilihat dari terbentuknya dua website resmi, yaitu wWw.wakatobitourism.com sebagai website resmi dinas yang dikelola langsung instansiini yang memuat informasi mengenai pariwisata Wakatobi sedangkan untuk infromasi kegiatan pemerintah tersedia dalam website pemerintah daerah yaitu www.wakatobikab.go.id. secara umum dalam pelaksanaan promosi wisata pemerintah daerah Wakatobi melibatkan semua pihak baik dari kalangan Akademis,kalangan bisnis, masyarakat, pemerintah pusat dan daerah serta NGO seperti Swisscontact, Lembaga Internasional JICA dan komunitas yang ada di Kabupaten Wakatobi. Hal ini sebagai sebuah konsekuensi dari banyaknya potensi wisata yang dimiliki Kabupaten Wakatobi yang tidak bisa bekerja sendiri menanganinya.

Saran yang dapat diberikan mengenai jurnal penelitian ini yaitu dapat dikaji lebih jauh lagi tentang peran pemerintah dalam mempromosikan destinasi-destinasi di wakatobi dalam hal media twitter dan facebook agar promosinya lebih aktif lagi, tidak hanya aktif promosi di instagram, karena facebook merupakan media soaial yang banyak penggunanya. Selain itu juga perlu di buat akun channel youtube agar promosinya lebih meluas lagi.

\section{Referensi}

[1]Ramadhan, W. O. J., Sudirman, F. A., Saidin, S., \& Susilawaty, F. T. (2020). Promosi Kuliner Jepang Melalui Media Sosial Sebagai Bentuk Diplomasi Publik: Studi Facebook Kedutaan Besar Jepang di Indonesia. Jurnal Ilmu Komunikasi UHO: Jurnal Penelitian Kajian Ilmu Komunikasi dan Informasi, 5(1), 63-75.

[2] Sudirman, F. A., Sarma, W. O. D., \& Susilawaty, F. T. PROMOSI PARIWISATA MELALUI DIGITAL DIPLOMACY: UPAYA 
INTERNASIONALISASI PARIWISATA DAERAH. Jurnal Ilmu Komunikasi UHO: Jurnal Penelitian Kajian Ilmu Komunikasi dan Informasi, 5(3), 174-185. 